\title{
N-Hydroxyphthalimide-Catalyzed Electrochemical Allylic Oxidation
}

\section{Gategory}

Organo- and

Biocatalysis

\section{Key words}

electrochemistry

allylic oxidation

cyclohexenones

hydroxysuccinimides

hydroxyphthalimide

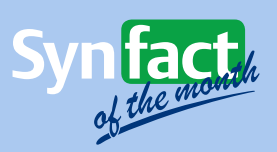

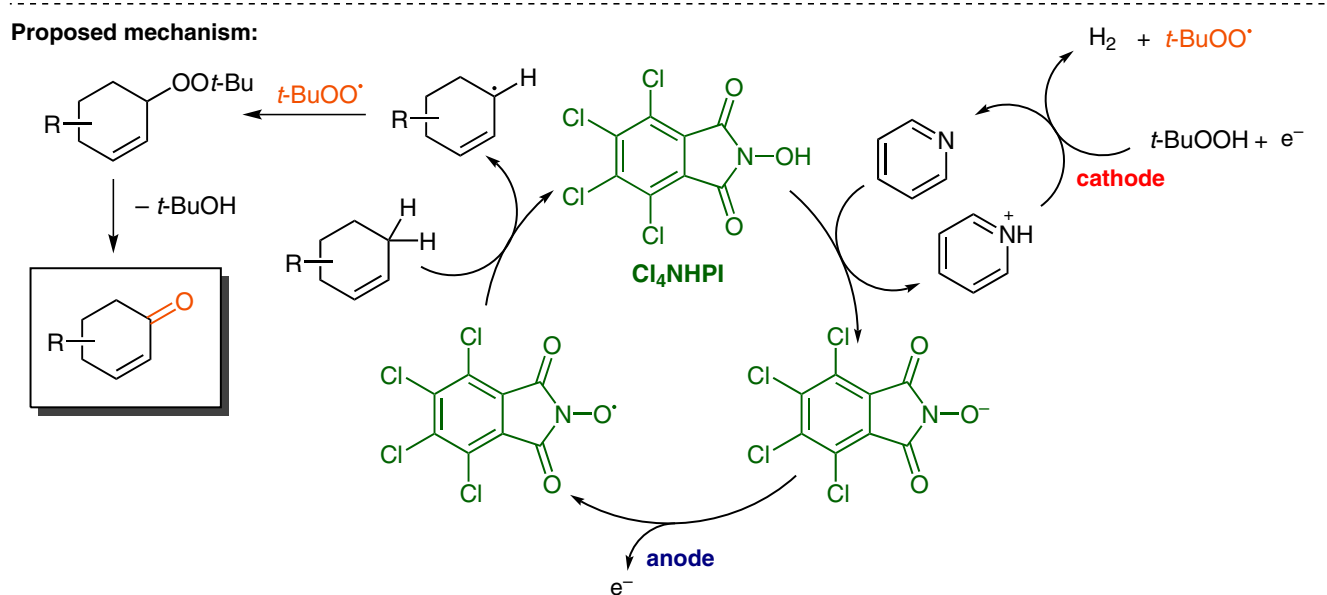

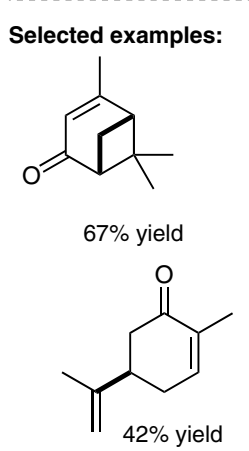

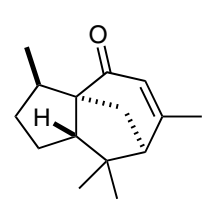

$53 \%$ yield

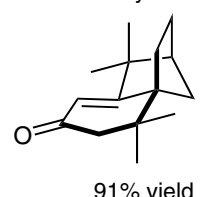

$91 \%$ yield
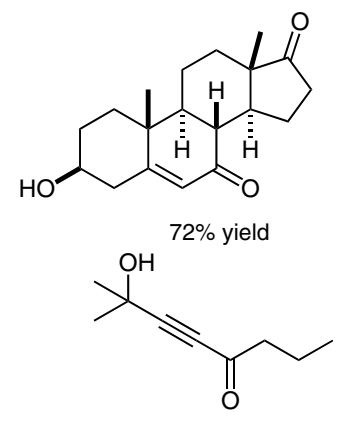

$52 \%$ yield
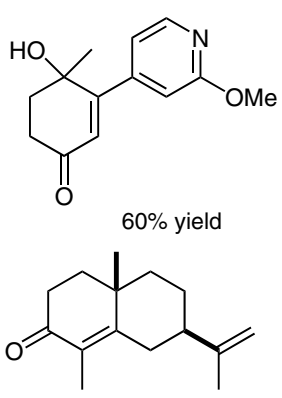

$51 \%$ yield
Significance: The Baran group reports an electrochemical oxidation of allylic methylene groups to give unsaturated ketones with $t-\mathrm{BuOOH}$ as the terminal oxidant. Anodic oxidation of the $\mathrm{N}$-hydroxyphthalimide catalyst $\left(\mathbf{C l}_{\mathbf{4}} \mathbf{N H P I}\right)$ is proposed to give an oxyl radical species. Upon abstraction of a hydrogen atom from the substrate, the resulting allylic radical is suggested to further react with a tert-butyl peroxyl radical to give the product after elimination of $t-\mathrm{BuOH}$.

SYNFACTS Contributors: Benjamin List, Tim Gatzenmeier Synfacts 2016, 12(08), 0855 Published online: 19.07.2016 Dol: 10.1055/s-0035-1562695; Reg-No.: B04316SF
Comment: Atom-economical and sustainable methods for allylic oxidations on an industrial scale are rare and cumbersome. This report suggests a catalyst-controlled electrochemical approach and aims for a simple and chemoselective solution. Although the isolated yields remain moderate in some cases, the broad scope as well as the low cost and toxicity of the materials render this methodology an auspicious alternative for large-scale applications. 